\title{
Magnetic properties of cobalt ferrite-silica nanocomposites prepared by a sol-gel autocombustion technique
}

Cannas, C.; Musinu, A.; Piccaluga, G.; Fiorani, D.; Peddis, Davide; Rasmussen, Helge Kildahl; Mørup, Steen

Published in:

Journal of Chemical Physics

Link to article, DOI:

$10.1063 / 1.2354475$

Publication date:

2006

Document Version

Publisher's PDF, also known as Version of record

Link back to DTU Orbit

Citation (APA):

Cannas, C., Musinu, A., Piccaluga, G., Fiorani, D., Peddis, D., Rasmussen, H. K., \& Mørup, S. (2006). Magnetic properties of cobalt ferrite-silica nanocomposites prepared by a sol-gel autocombustion technique. Journal of Chemical Physics, 125(16), 164714. https://doi.org/10.1063/1.2354475

\section{General rights}

Copyright and moral rights for the publications made accessible in the public portal are retained by the authors and/or other copyright owners and it is a condition of accessing publications that users recognise and abide by the legal requirements associated with these rights.

- Users may download and print one copy of any publication from the public portal for the purpose of private study or research.

- You may not further distribute the material or use it for any profit-making activity or commercial gain

- You may freely distribute the URL identifying the publication in the public portal 


\title{
Magnetic properties of cobalt ferrite-silica nanocomposites prepared by a sol-gel autocombustion technique
}

\author{
C. Cannas, A. Musinu, and G. Piccaluga \\ Dipartimento di Scienze Chimiche, Cittadella Universitaria di Monserrato, bivio per Sestu, \\ 09042 Monserrato (Cagliari), Italy \\ D. Fiorani \\ Istituto di Struttura della Materia-CNR, C.P. 10, 00016 Monterotondo Stazione (Roma), Italy \\ D. Peddis ${ }^{\text {a) }}$ \\ Dipartimento di Scienze Chimiche, Cittadella Universitaria di Monserrato, bivio per Sestu, \\ 09042 Monserrato (Cagliari), Italy, and Department of Physics, Technical University of Denmark, \\ DK-2800 Kongens Lyngby, Denmark \\ H. K. Rasmussen and S. Mørup \\ Department of Physics, Technical University of Denmark, DK-2800 Kongens Lyngby, Denmark
}

(Received 1 May 2006; accepted 18 August 2006; published online 27 October 2006)

The magnetic properties of cobalt ferrite-silica nanocomposites with different concentrations $(15,30$, and $50 \mathrm{wt} \%)$ and sizes $(7,16$, and $28 \mathrm{~nm})$ of ferrite particles have been studied by static magnetization measurements and Mössbauer spectroscopy. The results indicate a superparamagnetic behavior of the nanoparticles, with weak interactions slightly increasing with the cobalt ferrite content and with the particle size. From high-field Mössbauer spectra at low temperatures, the cationic distribution and the degree of spin canting have been estimated and both parameters are only slightly dependent on the particle size. The magnetic anisotropy constant increases with decreasing particle size, but in contrast to many other systems, the cobalt ferrite nanoparticles are found to have an anisotropy constant that is smaller than the bulk value. This can be explained by the distribution of the cations. The weak dependence of spin canting degree on particle size indicates that the spin canting is not simply a surface phenomenon but also occurs in the interiors of the particles. (C) 2006 American Institute of Physics. [DOI: 10.1063/1.2354475]

\section{INTRODUCTION}

The unique properties of nanoscaled magnetic particles have generated much interest because of their applications in high density data storage, ${ }^{1}$ ferrofluid technology, ${ }^{2}$ catalysts, color imaging, ${ }^{3}$ and magnetically guided drug delivery. ${ }^{4} \mathrm{An}$ understanding of the relationship between structure, particle size, and magnetic properties is essential in order to design new magnetic materials. In this context, superparamagnetic relaxation ${ }^{5}$ is one of the most important effects related to the reduction of particle size. Furthermore, the presence of noncollinear (canted) spin structures is also important in, for example, nanoparticles of ferrimagnetic materials. The presence of canted spins leads to modifications of the magnetic properties and for this reason spin canting has been intensively studied for more than 30 years. $^{6-8}$ It has been suggested that the spin canting is a surface phenomenon, ${ }^{9,10}$ and therefore it should become increasingly important with decreasing particle size. However, some studies rather indicate that the noncollinear spin structure is a finite size effect which also occurs in the interior of the particles. ${ }^{11}$

Among nanoscaled magnetic materials, nanoparticles of spinel ferrites are of great interest, not only because of their technological applications but also from the point of view of

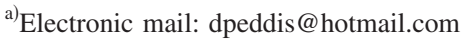

fundamental science. In fact, they are good model systems for studies of the relationship between magnetic behavior and magnetic structure at atomic level. ${ }^{12}$ In addition, the structural properties and the rich crystal chemistry of spinels offer excellent opportunities for understanding and fine tuning the magnetic properties. ${ }^{13}$

The ferrite spinel structure $\left(M^{\mathrm{II}} \mathrm{Fe}_{2} \mathrm{O}_{4}\right)$ is based on a closed-packed oxygen lattice, in which tetrahedral (called $A$ sites) and octahedral (called $B$ sites) interstices are occupied by the cations. The physical behavior and, in particular, the magnetic properties depend on the cationic distribution in the $A$ and $B$ sites. Spinels with only divalent ions in tetrahedral sites are called normal, while compounds with the divalent ions in the octahedral sites are called inverse. In general, the cationic distribution in octahedral and tetrahedral sites may be quantified by the inversion degree, which is defined as the fraction of divalent ions in the octahedral sites. ${ }^{14} \mathrm{An}$ important topic in the physical-chemistry study of spinel ferrites is the understanding of the factors that affect the cationic distribution and the control of it. The inversion degree may depend on the thermal history of the materials ${ }^{15}$ and also on particle size effects. ${ }^{16}$

The use of an inorganic nonmagnetic matrix (e.g., amorphous silica) as a host for nanoparticles can provide a way to control morphological, structural, and consequently physical properties of nanocomposite materials. ${ }^{17}$ The presence of a 

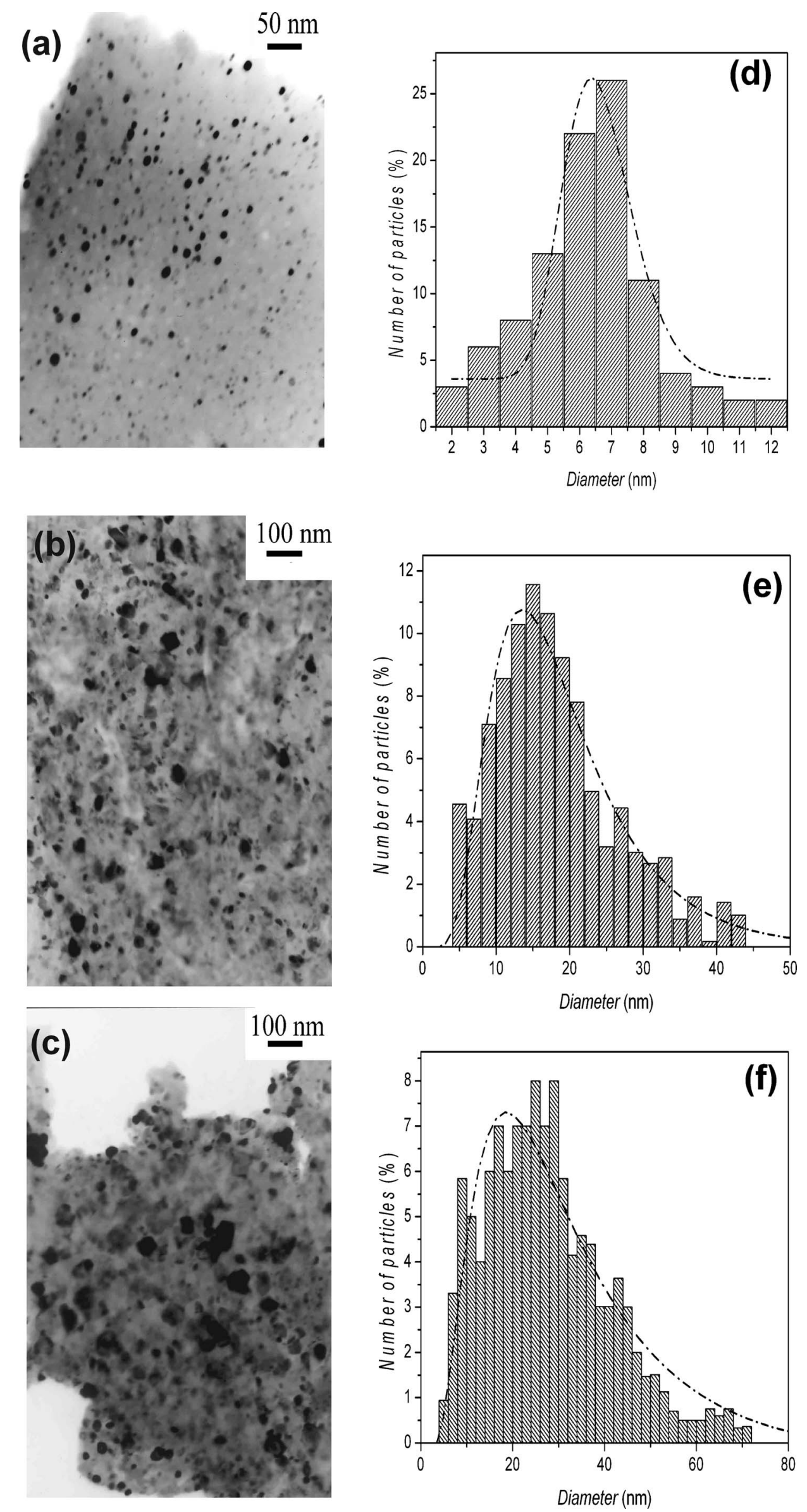

FIG. 1. TEM dark-field images (left side) and distribution of particle size (right side) of the N15 [(a)-(d)], N30 [(b)-(e)], and N50 [(c)-(f)] samples. 
TABLE I. Mean particles size obtained from TEM images $\left(\left\langle D_{\text {TEM }}\right\rangle\right)$, temperature corresponding to the maximum in ZFC curve $\left(T_{\max }\right)$, irreversibility temperature $\left(T_{\text {irr }}\right)$, blocking temperature from TRM measurement $\left(T_{B}^{m}\right)$, and blocking temperature from Mössbauer spectroscopy $\left(T_{B}^{M}\right)$. Uncertainties are given in parentheses as errors on the last digit.

\begin{tabular}{lcccccc}
\hline \hline Sample & Acronym & $\begin{array}{c}<D_{\mathrm{TEM}}> \\
(\mathrm{nm})\end{array}$ & $\begin{array}{c}T_{\max } \\
(\mathrm{K})\end{array}$ & $\begin{array}{c}T_{\text {irr }} \\
(\mathrm{K})\end{array}$ & $\begin{array}{c}T_{B}^{m} \\
(\mathrm{~K})\end{array}$ & $\begin{array}{c}T_{B}^{M} \\
(\mathrm{~K})\end{array}$ \\
\hline $\mathrm{CoFe}_{2} \mathrm{O}_{4} / \mathrm{SiO}_{2} 15$ wt \% & $\mathrm{N} 15$ & $6.7(1)$ & $53(1)$ & $85(2)$ & $26(1)$ & $127(10)$ \\
$\mathrm{CoFe}_{2} \mathrm{O}_{4} / \mathrm{SiO}_{2} 30$ wt $\%$ & $\mathrm{~N} 30$ & $16.3(7)$ & $127(3)$ & $231(4)$ & $60(2)$ & $213(10)$ \\
$\mathrm{CoFe}_{2} \mathrm{O}_{4} / \mathrm{SiO}_{2} 50$ wt $\%$ & $\mathrm{~N} 50$ & $28.3(8)$ & $207(4)$ & $298(5)$ & $134(4)$ & $236(10)$ \\
\hline \hline
\end{tabular}

host matrix may reduce nanoparticle aggregation. ${ }^{18}$ In addition, nanocomposites may have many advantages from a technological point of view, allowing to improve catalytic, ${ }^{19}$ magnetic, ${ }^{20}$ magneto-optic, ${ }^{21}$ and mechanical properties ${ }^{22}$ of the material.

We have prepared cobalt ferrite-silica nanocomposites with a wide range of compositions through a novel synthesis method that combines the traditional sol-gel methods and the nitrate-citrate autocombustion method. ${ }^{23,24}$ In this paper we present a study of samples with $15 \%, 30 \%$, and $50 \%$ w/w of magnetic phase in order to investigate the magnetic properties of these new materials, with particular attention to the effect of silica content; we also focus on the relationship among inversion degree, particle size, and magnetic properties. Finally, we approach the problem of the spin canting in relation to particle size.

\section{EXPERIMENTAL TECHNIQUES AND SAMPLE CHARACTERIZATION}

A detailed description of the synthesis procedure is given elsewhere. ${ }^{23,24} \mathrm{An}$ aqueous solution of iron and cobalt nitrates $(\mathrm{Fe}: \mathrm{Co}=2: 1)$ and citric acid $(\mathrm{CA})$ with $1: 1$ molar ratio of metals to CA was prepared and aqueous ammonia was added up to $p \mathrm{H} \sim 2$. A silica precursor, tetraethoxysilane (TEOS) in ethanol, was added and, after vigorous stirring for $30 \mathrm{~min}$, the sols were allowed to gel in static air at $40^{\circ} \mathrm{C}$ in an oven for $24 \mathrm{~h}$. Subsequently, the gels were submitted to a thermal treatment at $300{ }^{\circ} \mathrm{C}$ in a preheated oven for $15 \mathrm{~min}$ and a flameless autocombustion reaction occurred. Then the temperature was raised up to $900{ }^{\circ} \mathrm{C}$ with steps of $100{ }^{\circ} \mathrm{C}$ and the samples were kept for $1 \mathrm{~h}$ at each temperature. The results of inductively coupled plasma (ICP) analysis confirmed for the samples treated at $900{ }^{\circ} \mathrm{C}$ both the molar nominal ratio magnetic phase/silica and the nominal composition of the magnetic phase. In the following, the samples treated at $900{ }^{\circ} \mathrm{C}$ will be referred to as $\mathrm{N} X(X=50,30,15)$.

dc magnetization measurements were performed with a Quantum Design superconducting quantum interference device (SQUID) magnetometer, equipped with a superconducting coil which could produce magnetic fields in the range from -5 to $+5 \mathrm{~T}$. dc magnetization versus temperature measurements were performed using the zero field cooled (ZFC), field cooled (FC), and thermoremanent magnetization (TRM) protocols. Zero field cooled and field cooled magnetization measurements were carried out by cooling the sample from room temperature to $4.2 \mathrm{~K}$ in zero magnetic field; then a static magnetic field of $5 \mathrm{mT}$ was applied. $M_{\mathrm{ZFC}}$ was mea- sured during warming up from 4.2 to $325 \mathrm{~K}$, whereas $M_{\mathrm{FC}}$ was recorded during the subsequent cooling. In the TRM measurements, the sample was cooled from 325 to $4.2 \mathrm{~K}$ in an external magnetic field of $5 \mathrm{mT}$; then the field was turned off and magnetization was measured on warming up.

The measurements of magnetization as a function of magnetic field were carried out at $4.2 \mathrm{~K}$ in fields between -5 and $+5 \mathrm{~T}$ for all the samples. The samples in the form of powders were immobilized in an epoxy resin to prevent any movement of the nanoparticles during the measurements. The saturation magnetization value $\left(M_{s}\right)$ was obtained by fitting the high-field part of the hysteresis curve using the relation $^{25}$

$$
M=M_{s}\left(1-\frac{a}{B}-\frac{b}{B^{2}}\right) .
$$

$B$ is the field strength and $a$ and $b$ parameters are determined by the fitting procedure.

The Mössbauer spectra were obtained using constantacceleration spectrometers with $50 \mathrm{mCi}$ sources of ${ }^{57} \mathrm{Co}$ in rhodium. The spectrometers were calibrated with a $12.5 \mu \mathrm{m}$ $\alpha$-Fe foil at room temperature, and isomer shifts are given with respect to that of $\alpha$-Fe at room temperature. The Mössbauer spectra, measured below $80 \mathrm{~K}$, were obtained using a closed cycle helium refrigerator from APD Cryogenics Inc., and the spectra obtained between 80 and $295 \mathrm{~K}$ were obtained using a liquid nitrogen cryostat. Spectra in a magnetic field of $6 \mathrm{~T}$ applied parallel to the gamma ray direction were obtained using a liquid helium cryostat with a superconducting coil.

\section{RESULTS}

\section{A. Structural and morphological characterization}

A comprehensive structural and textural analysis of the samples by use of $\mathrm{x}$-ray diffraction (XRD) and transmission electron microscopy (TEM) is given elsewhere. ${ }^{23}$ Here we give only some results that are necessary for understanding the magnetic data. The XRD patterns showed the presence of the main reflections attributable to the cubic cobalt ferrite phase, superimposed to an amorphous silica halo. The presence of the background due to the amorphous silica did not permit to obtain reliable values of particle size from XRD measurement. The TEM images [Figs. 1(a)-1(c)] show for all the samples the presence of nanocrystalline particles dispersed in a silica host matrix. The particle size distributions [Figs. 1(d)-1(f)] are fitted with log-normal functions and the mean particle sizes $\left(\left\langle D_{\mathrm{TEM}}\right\rangle\right)$ are reported in Table I. The 

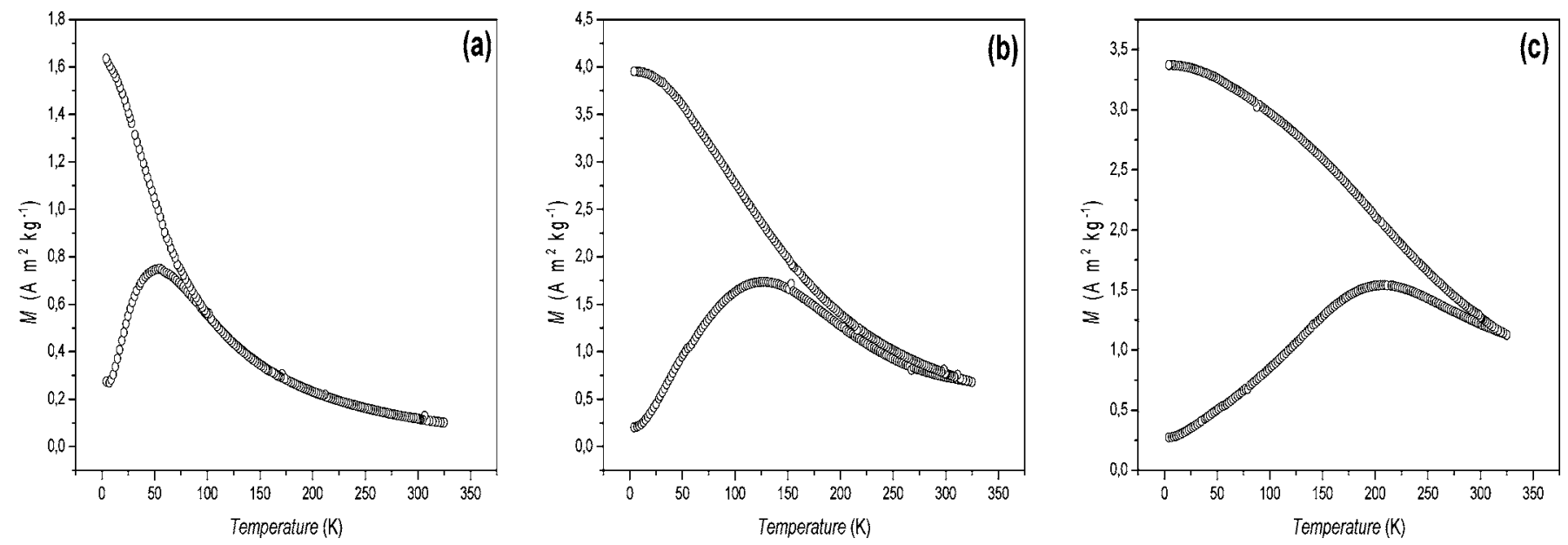

FIG. 2. Zero field cooled-field cooled measurements in external magnetic field of $5 \mathrm{mT}$ for samples N15 (a), N30 (b), and N50 (c).

$\left\langle D_{\mathrm{TEM}}\right\rangle$ values indicate that the increase of ferrite content leads to an increase of particle size and a gradual broadening of size distribution, in agreement with a previous study. ${ }^{26}$

\section{B. Magnetic measurements}

Figures 2(a)-2(c) show magnetization measurements carried out with the ZFC-FC protocol for the samples N15, N30, and N50, respectively. The measurements show for all the samples an irreversible magnetic behavior below a given temperature, called the irreversibility temperature $\left(T_{\mathrm{irr}}\right) . T_{\mathrm{irr}}$ is related to the blocking of the biggest particles, ${ }^{27}$ and we define it as the temperature where the difference between $M_{\mathrm{FC}}$ and $M_{\mathrm{ZFC}}$, normalized to its maximum value at the minimum temperature $(4.2 \mathrm{~K})$, becomes smaller than $3 \%$. The ZFC curves exhibit a maximum and the corresponding temperature $\left(T_{\max }\right)$ is for noninteracting particles directly proportional to the average blocking temperature with a proportionality constant $(\beta=1-2)$ that depends on the type of size distribution. Therefore, $T_{\max }$ is related to the blocking of particles with the mean particle size. ${ }^{28}$ The difference between $T_{\max }$ and $T_{\text {irr }}$ provides a qualitative measure of the width of blocking temperature distribution (i.e., of the size distribution in the absence of interparticle interactions). ${ }^{27}$ In Table I we report $T_{\max }$ and $T_{\text {irr. }}$ (for the sample N50, $T_{\text {irr }}$ may be slightly larger than the value given in the Table I, because the measurements were only made up to $325 \mathrm{~K}$ and there is no clear coincidence of the FC and ZFC curves below this temperature). For samples N15 and N30, a fitting of the difference between FC and ZFC magnetization curves, which is correlated to the distribution of blocking temperatures, ${ }^{5}$ was performed maintaining the anisotropy constant as a fixed parameter and varying the parameters of the distribution volume function (log normal) (Fig. 3, inset). This allowed us to derive the distribution of blocking temperatures (Fig. 3).

$T_{\text {irr }}$ and $T_{\max }$ increase with the increase of ferrite content, and this trend can be explained by the increase of particle size and also by an increase of interparticle interactions, as they lead to an increase of the effective anisotropy energy. Actually, the behavior of the FC susceptibility (it increases with decreasing temperature even below $T_{\max }$ ) indicates that the interparticle interactions are negligible in the most di- luted sample, N15, and weak in the other two samples, although it is not possible to obtain quantitative information from these measurements. Indeed, for sample N15, the FC magnetization shows a behavior very close to that of an assembly of noninteracting particles, i.e., a Curie-law behavior. On the other hand, the low temperature progressive deviation from a Curie-type behavior (downward curvature) observed in N30 sample and more marked in N50 sample indicates that some weak interparticle interactions (weaker in N30) are present. Indeed, in case of strong interparticle interactions, the FC magnetization would exhibit a temperature independent behavior below $T_{\max }$, as signature of a collective-type blocking of particle moments. ${ }^{29}$

Figures 4(a)-4(c) show measurements of the magnetization as a function of temperature, carried out with the TRM procedure. For all the samples, $M_{\mathrm{TRM}}$ decreases with increasing temperature, and for N15 and N30 it vanishes above 108 and $180 \mathrm{~K}$, respectively, whereas N50 shows a nonzero value in the whole temperature range, indicating that the largest particles are blocked even at room temperature.

For an assembly of noninteracting particles, the derivative of $M_{\text {TRM }}$ with respect to temperature gives an estimate of the anisotropy energy barrier distribution, ${ }^{30,31}$

$$
f\left(\Delta E_{a}\right) \propto-\frac{d M_{\mathrm{TRM}}}{d T} .
$$

Figures 4(d)-4(f) show the $\Delta E_{a}$ distribution (continuous lines) for the three samples, moving towards higher values with increasing particle size, and the fits with a log-normal function (dotted line) for the samples N30 and N15. Actually, the derivative of $M_{\mathrm{TRM}}$ can be considered as representative of the $\Delta E_{a}$ distribution for the N15 and N30 samples, where the interparticle interactions are negligible and very weak, respectively, but not for the N50 sample. Because of the very irregular trends, it is not possible make a reliable fitting for this sample. The obtained distribution for samples N15 and N30 is well consistent with the distribution of blocking temperatures derived from FC/ZFC magnetization measurements. ${ }^{32}$ The decrease of ferrite content leads to a more regular distribution of anisotropy energy barrier that approaches more and more to log-normal function. 

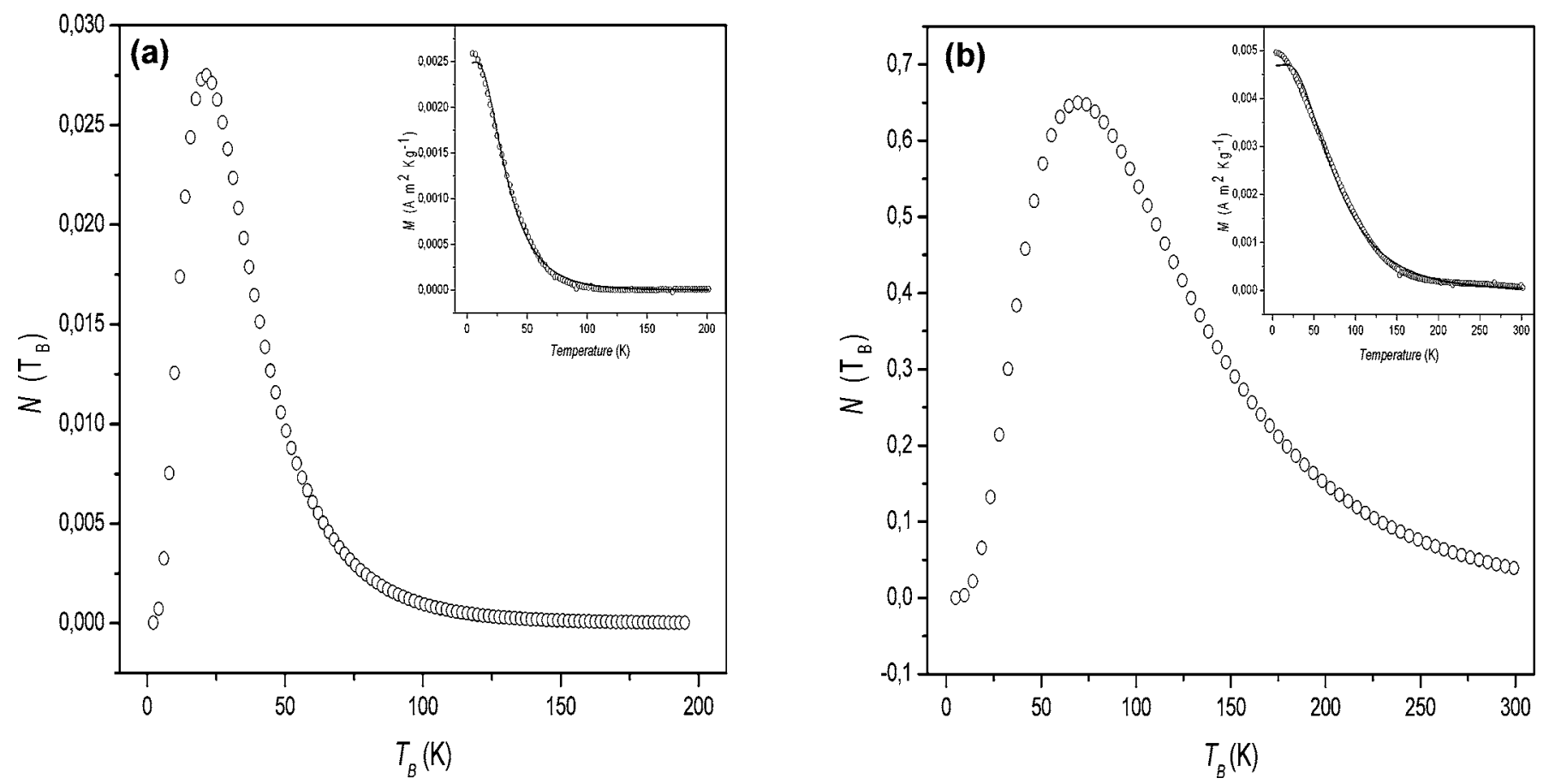

FIG. 3. Distribution of blocking temperatures for samples N15 (a) and N30 (b) derived from the fitting of the temperature dependence of the difference between FC and ZFC magnetizations (inset).
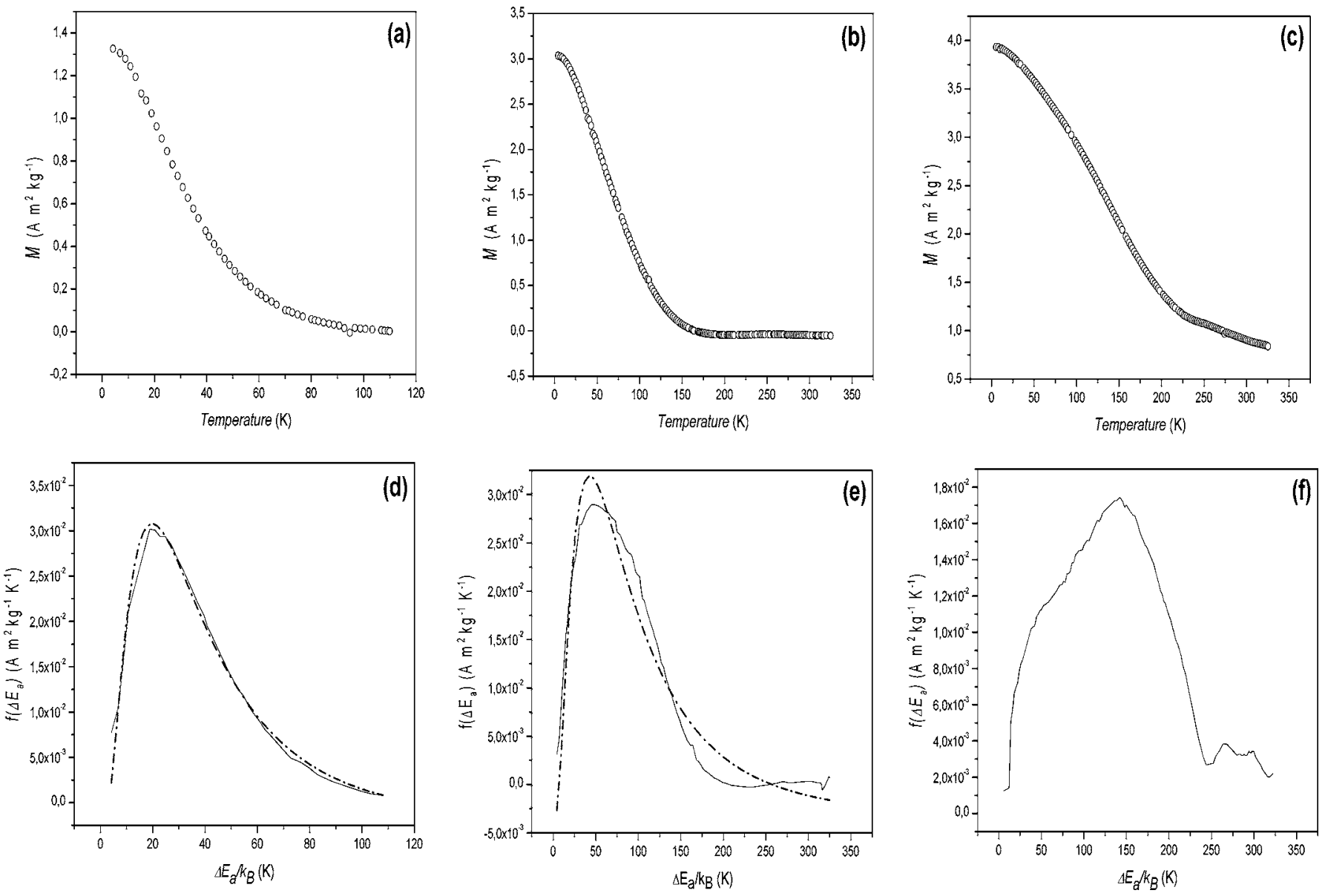

FIG. 4. TRM measurements and distribution of magnetic anisotropy energy for samples N15 [(a) and (d)], N30 [(b) and (e)], and N50 [(c) and (f)]. 

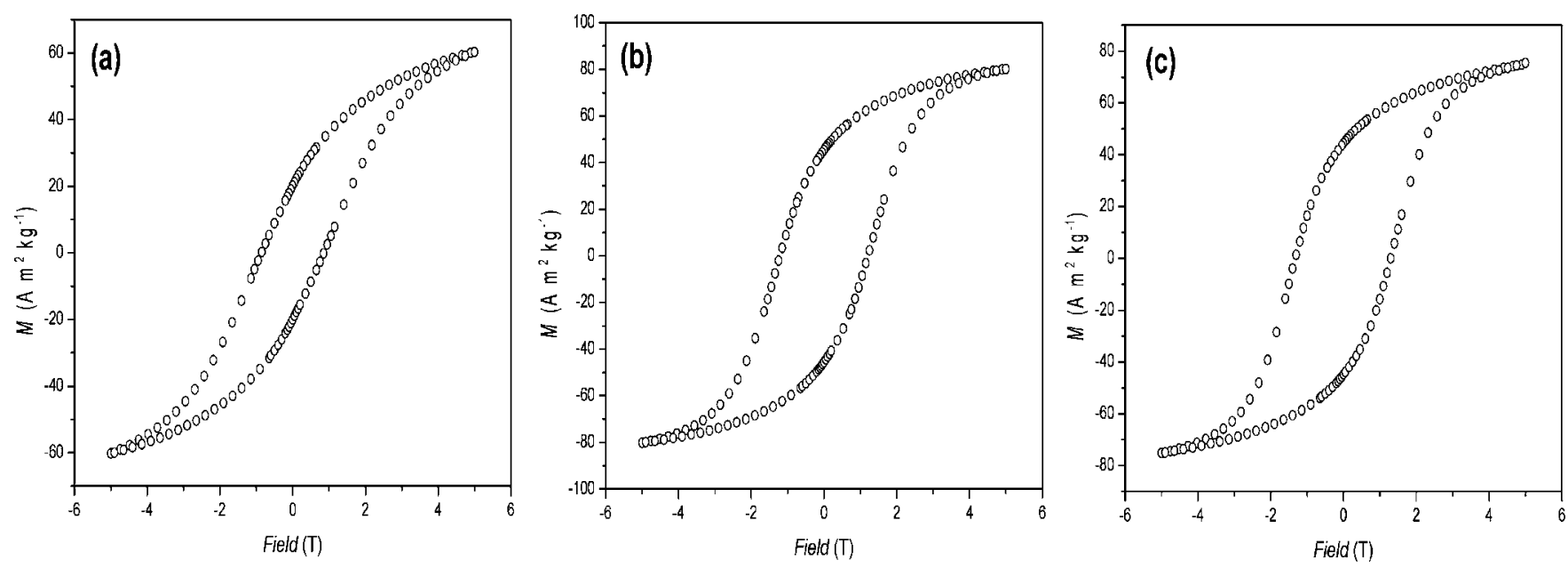

FIG. 5. Hysteresis loops of samples N15 (a), N30 (b), and N50 (c) at $4.2 \mathrm{~K}$.

For noninteracting particles with uniaxial magnetic anisotropy, the superparamagnetic relaxation can be described by the Néel expression:

$$
\tau=\tau_{0} \exp \left(\frac{K V}{k_{B} T}\right),
$$

where $k_{B}$ is the Boltzmann constant, $T$ is the absolute temperature, $K$ is the magnetic anisotropy constant, and $V$ is the particle volume. $\tau_{0}$ is typically of the order of $10^{-9}-10^{-13} \mathrm{~s}^{33,34}$ The blocking temperature $\left(T_{B}\right)$ can be defined as the temperature for which the relaxation time $(\tau)$ is equal to the measuring time of the experimental technique. In practice, samples of small particles always exhibit particle size distributions, and often $T_{B}$ is defined as the temperature at which $50 \%$ of the sample is in the superparamagnetic state. ${ }^{31,34}$ We can obtain an estimate of the blocking temperature from the distribution of magnetic anisotropy energy barriers, evaluating the temperature at which $50 \%$ of the particles overcome their anisotropy energy barriers. In Table I the values of the blocking temperature $\left(T_{B}^{m}\right)$ obtained with this method are reported. Actually, the blocking temperature obtained for N50 is less reliable, due to the presence of interparticle interactions, although weak, and in any case it is underestimated because the explored temperature range does not allow observation of the magnetic anisotropy for the biggest particles. For N15 and N30 samples, the ratio between $T_{\max }$ and $T_{B}^{m}$ is $=2$, within the expected $\beta$ values.

Figures 5(a)-5(c) show the dependence of the magnetization on the field (hysteresis loops) in the range of $\pm 5 \mathrm{~T}$ at $4.2 \mathrm{~K}$ for samples N15, N30, and N50, respectively. In Table II the saturation magnetization $\left(M_{s}\right)$ obtained by relation (1), the coercive field $\left(H_{c}\right)$, the remanent magnetization $\left(M_{r}\right)$, and the reduced remanent magnetization $\left(M_{r} / M_{s}\right)$ are reported. For samples N50 and N30, the values of $M_{s}$ and $H_{c}$ are very similar and the $M_{r} / M_{s}$ ratio is very close to 0.5 , the value expected, according to the Stoner-Wolfarth, for an assembly of noninteracting particles with uniaxial anisotropy axes randomly distributed. This is coherent with the presence of weak interactions ${ }^{34,35}$ and the absence of multiaxial anisotropy as observed in other samples of $\mathrm{CoFe}_{2} \mathrm{O}_{4}$ nanoparticles. ${ }^{36}$ For sample N15, although the particles are not interacting, a lower $M_{r} / M_{s}$ value is observed, probably due to the presence of very small particles still in the superparamagnetic state at $4.2 \mathrm{~K}$. This is consistent with the size distribution shown in Fig. 1(d).

\section{Mössbauer measurements}

Mössbauer spectra of noninteracting or weakly interacting magnetic nanoparticles typically consist of a superposition of a sextet due to particles with superparamagnetic relaxation time long compared to the time scale of Mössbauer spectroscopy $\left(\tau_{M} \approx 5 \times 10^{-9} \mathrm{~s}\right)$ and a doublet due to particles with shorter relaxation times. The relative area of the doublet increases with increasing temperature. However, in samples with strong interactions between the particles, the spectra typically consist of sextets in a broad range of temperatures, but with increasing temperature the lines become broadened and the average hyperfine splitting decreases. ${ }^{37,38}$

Figures 6(a)-6(c) show Mössbauer spectra for samples $\mathrm{N} 15, \mathrm{~N} 30$, and N50, respectively, in zero applied magnetic field at different temperatures. At low temperatures, the spectra show magnetically split sextets, but with increasing temperatures there is a gradual collapse of the six lines to a doublet component because of the fast superparamagnetic relaxation of the nanoparticles. The evolution of the spectra with temperature indicates that the magnetic anisotropy energy is predominant compared to the interaction energy. ${ }^{37,38}$ The blocking temperature $\left(T_{B}^{M}\right)$ can be defined as the temperature at which $50 \%$ of the spectral area is magnetically split. ${ }^{33}$ The values of $T_{B}^{M}$ were estimated by fitting the spectra

TABLE II. Parameters obtained from the hysteresis loops: saturation magnetization $\left(M_{s}\right)$, coercive field $\left(H_{c}\right)$, remanent magnetization $\left(M_{r}\right)$, and reduced remanent magnetization $\left(M_{r} / M_{s}\right)$. Uncertainties are given in parentheses as errors on the last digit.

\begin{tabular}{ccccc}
\hline \hline Sample & $\begin{array}{c}M_{r} \\
\left(\mathrm{~A} \mathrm{~m}^{2} \mathrm{~kg}^{-1}\right)\end{array}$ & $\begin{array}{c}M_{s} \\
\left(\mathrm{~A} \mathrm{~m}^{2} \mathrm{~kg}^{-1}\right)\end{array}$ & $M_{r} / M_{s}$ & $H_{c}(\mathrm{~T})$ \\
\hline N15 & $20.0(1)$ & $78(1)$ & 0.26 & $0.87(1)$ \\
N30 & $44.6(1)$ & $89.3(2)$ & 0.50 & $1.2(1)$ \\
N50 & $44.5(1)$ & $89.5(3)$ & 0.50 & $1.3(1)$ \\
\hline \hline
\end{tabular}




\section{N15}

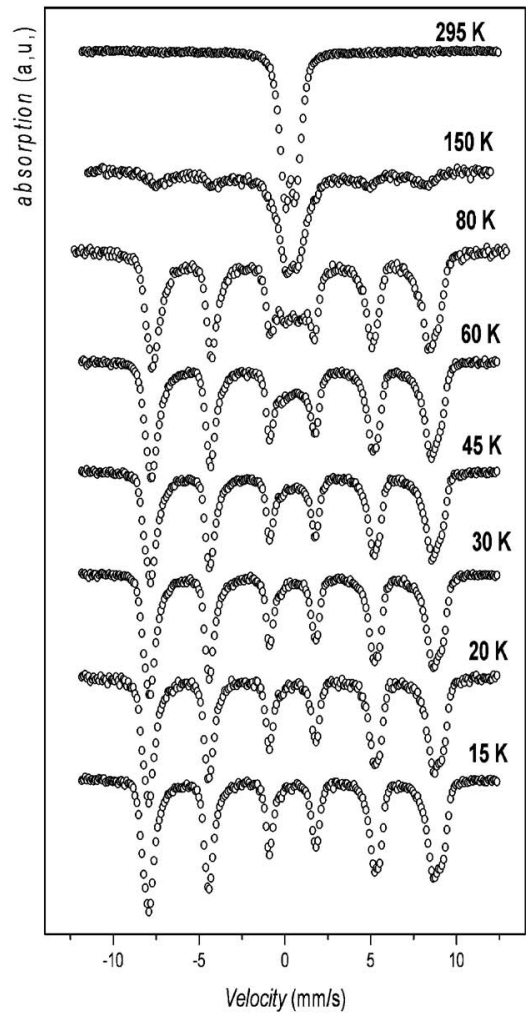

N30

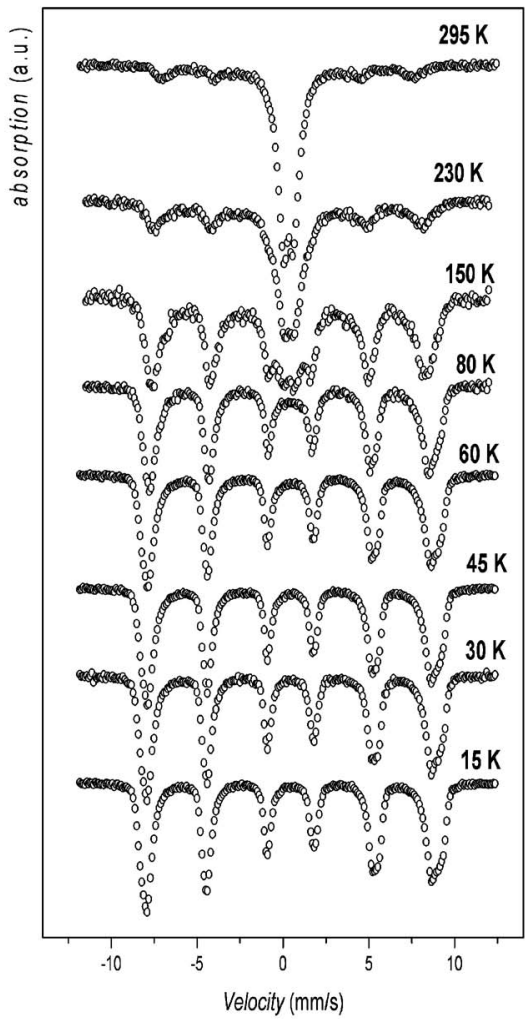

N50

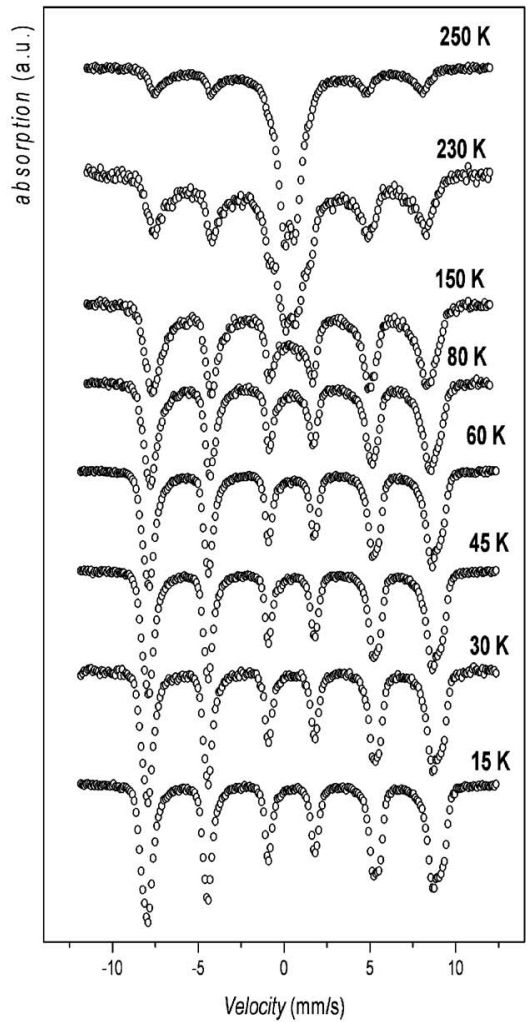

FIG. 6. Mössbauer spectra in zero magnetic field recorded at different temperatures for samples N15, N30, and N50.

with sextets and doublets and are reported in Table I. The values of $T_{B}^{M}$ decrease with increasing silica content, in agreement with the trend of $T_{B}^{m}$ obtained from magnetization measurement.

The low-temperature spectra show an asymmetry due to a small difference in the Mössbauer parameters of ions in the $A$ and $B$ sites in the spinel structure. In the temperature range of $45-15 \mathrm{~K}$ for the N15 sample and between 60 and $15 \mathrm{~K}$ for the N50 and N30 samples, it is possible to fit the spectra with sextets that can be ascribed to the iron atoms in the $A$ and $B$ sites. However, because of the overlap of the lines, it was not possible to obtain reliable information about the cationic distribution from these spectra. As expected for small magnetic nanoparticles, we observe a decrease of the magnetic hyperfine field with increasing temperature due to collective magnetic excitations. ${ }^{39,40}$ Therefore, the observed magnetic hyperfine field is the average hyperfine field given by

$$
B_{\text {obs }}=B_{0}\langle\cos \theta\rangle,
$$

where $B_{0}$ is the magnetic hyperfine field in the absence of fluctuations and $\theta$ is the angle between the magnetization vector and the easy direction of magnetization. ${ }^{39,40}$ For noninteracting particles with uniaxial anisotropy, Eq. (4) can in the limit $K V \gg k_{B} T$ be written as

$$
B_{\text {obs }}(T)=B_{0}\left(1-\frac{k_{B} T}{2 K V}\right) .
$$

Figure 7 shows the thermal variation of the average hyperfine field $\left\langle B_{\text {obs }}\right\rangle$ (weighted average over $A$ and $B$ components) at temperatures well below the blocking temperature. All three samples show a linear trend in accordance with Eq. (5), and as expected the slope increases with decreasing particle size. The values of the anisotropy constants were estimated using Eq. (5) assuming spherical particle shapes with the diameters given in Table I. The values of $K$, which are reported in Table III, decrease with increasing particle size in

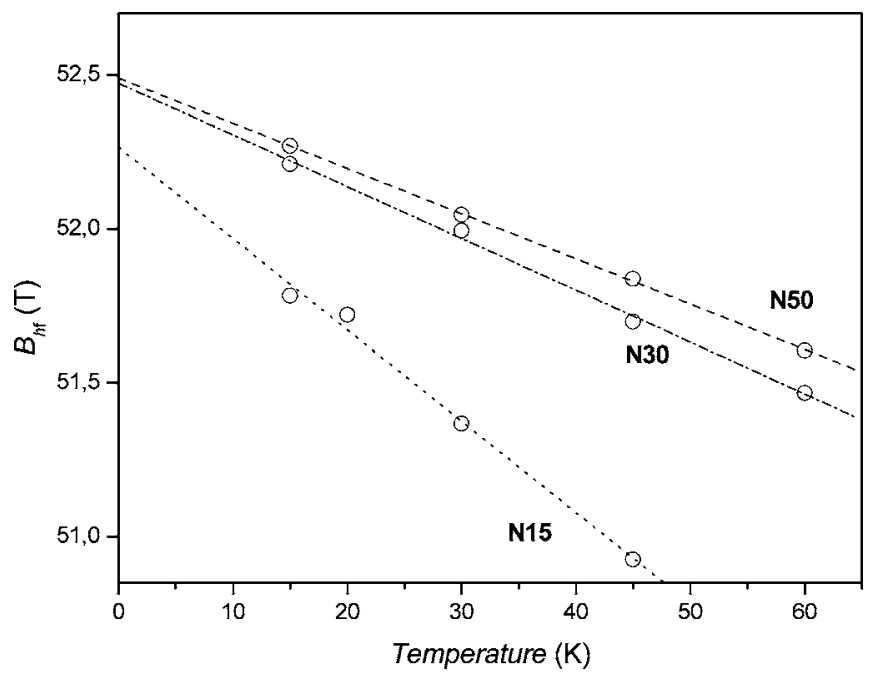

FIG. 7. Temperature dependence of the average hyperfine magnetic field for samples N50 (dashed line), N30 (dot-dashed line), and N15 (dotted line). 
TABLE III. The ratios of the blocking temperatures obtained from Mössbauer spectroscopy and the blocking temperatures from magnetization measurement $\left(T_{B}^{M} / T_{B}^{m}\right)$ and the temperature corresponding to the maximum in ZFC curve $\left(T_{B}^{M} / T_{\max }\right)$. The anisotropy constant obtained from the dependence $\left\langle B_{\mathrm{hf}}\right\rangle$ vs $T\left(K_{a}\right)$ and from a combined approach using Mössbauer and magnetization techniques $\left(\mathrm{K}_{b}\right)$.

\begin{tabular}{ccccc}
\hline \hline Sample & $T_{B}^{M} / T_{B}^{m}$ & $T_{B}^{M} / T_{\max }$ & $\begin{array}{c}K_{a} \\
\left(\mathrm{~J} / \mathrm{m}^{3}\right)\end{array}$ & $\begin{array}{c}K_{b} \\
\left(\mathrm{~J} / \mathrm{m}^{3}\right)\end{array}$ \\
\hline N15 & 4.88 & 2.39 & $6.8 \times 10^{4}$ & $7.7 \times 10^{4}$ \\
N30 & 3.55 & 1.67 & $1.2 \times 10^{4}$ & $9.5 \times 10^{3}$ \\
N50 & 1.82 & 1.17 & $8.2 \times 10^{3}$ & $2.1 \times 10^{3}$ \\
\hline \hline
\end{tabular}

accordance with earlier observations for nanoparticles of $\alpha$ $-\mathrm{Fe},{ }^{41} \alpha-\mathrm{Fe}_{2} \mathrm{O}_{3},{ }^{42}$ and $\gamma-\mathrm{Fe}_{2} \mathrm{O}_{3}{ }^{43}$ The estimated values of $K$ may be influenced by interparticle interactions, which can result in apparently larger values of the estimated anisotropy constants. $^{38,40}$

Mössbauer spectra of ferrites in large applied fields may allow a more reliable distinction between $A$ - and $B$-site components than the zero field spectra, because the applied field is usually added to the $A$-site hyperfine field and subtracted from the $B$-site hyperfine field. Therefore, there is less overlap between the two components in the high-field spectra. Furthermore, such spectra can also give information about the magnetic structure. In the presence of an external magnetic field parallel to the gamma ray direction, the relative areas of the six lines give information about the degree of alignment of the magnetization with the applied field. For a thin absorber the relative area of the six lines is given by $3: p: 1: 1: p: 3$, where

$$
p=\frac{4 \sin ^{2} \theta}{1+\cos ^{2} \theta}
$$

and $\theta$ is the angle between the magnetic field at the nucleus and the gamma ray direction.

Figure 8 shows Mössbauer spectra of samples N15 and $\mathrm{N} 30$ at $6 \mathrm{~K}$ and of sample $\mathrm{N} 50$ at $6 \mathrm{~K}$ and at $200 \mathrm{~K}$, all obtained with a magnetic field of $6 \mathrm{~T}$ applied parallel to the gamma ray direction. As expected, the spectra are clearly resolved in two main six-line components. Lines 2 and 5 have nonzero intensity and this suggests a noncollinear spin structure, i.e., some of the spins are not aligned parallel or antiparallel to the external magnetic field. ${ }^{6-8}$

When fitting such spectra with partly overlapping components, it is necessary to apply some constraints on, for example, the relative areas. A finite absorber thickness will result in a ratio between lines 1 and 6 and lines 3 and 4 that is less than 3. In order to minimize the error due to the thickness of the absorbers in the fitting, each spectrum was first fitted with four doublets. For each doublet, the line intensity and line widths were constrained to be equal in pairs and we estimated a ratio of $A_{1,6} / A_{3,4} \approx 2.8$ for all the spectra. This value was then used as a constraint in the fits with sextets. Several fitting procedures were used in order to investigate different possible models. In accordance with the presence of the iron atoms in tetrahedral ( $A$ sites) and octahedral ( $B$ sites) sites, the spectra were first fitted with two sextets. The parameter $p=A_{2,5} / A_{3,4}$ was free, assuming that

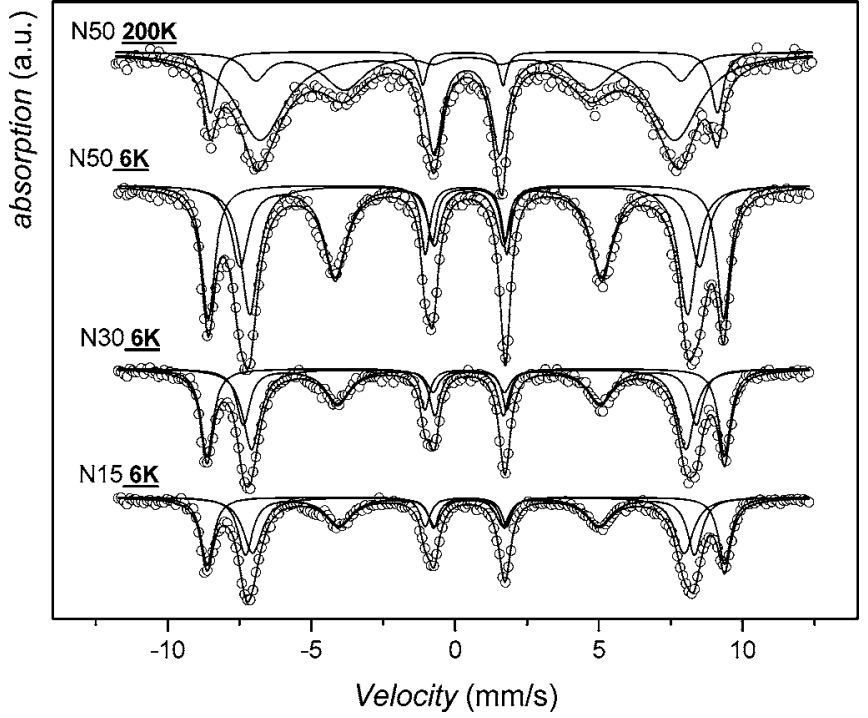

FIG. 8. Mössbauer spectra in an external magnetic field of $6 \mathrm{~T}$, recorded at $6 \mathrm{~K}$ for samples $\mathrm{N} 15$ and $\mathrm{N} 30$ and at $6 \mathrm{~K}$ and $200 \mathrm{~K}$ for sample N50.

the canting angle for the magnetic moments in the $A$ and $B$ sites are two independent parameters. The linewidths and line intensities were fixed to be equal in pairs. However, this model seemed to be too simple, and, in particular, the fitting of the positions of lines 2 and 5 was not satisfactory, indicating that other components were present. The spectra were therefore fitted with three sextets. The best results were obtained utilizing a model similar to that used previously for maghemite nanoparticles, tin-doped maghemite, ${ }^{44}$ and MnZn ferrite. ${ }^{45}$ Thus it was assumed that some of the iron atoms were in perfect ferrimagnetic local environments, and in accordance with this the relative areas of lines 2 and 5 were constrained to zero for two sextets (area ratio of 2.8:0:1:1:0:2.8) corresponding to $A$ (sextet 1 ) and $B$ (sextet 2) sites. A third sextet (sextet 3 ) was introduced to represent ions with canted spins, and in this component the parameter $p=A_{2,5} / A_{3,4}$ was free (area ratio of $2.8: p: 1: 1: p: 2.8$ ). In all three sextets the linewidths and line intensities were constrained to be pairwise equal. The Mössbauer parameters obtained from these fits are given in Table IV.

In the high-field spectra, obtained at low temperature, the values of total field at the nuclei, $B_{\text {eff }}$, the isomer shifts $(\delta)$, and the quadrupole shifts $(\varepsilon)$ for each sextet are very similar for the three samples, and this indicates that the magnetic structure of the nanoparticles is quite similar for all of them. In all samples, sextet 2 and sextet 3 show values of the isomer shifts typical for octahedrally coordinated $\mathrm{Fe}^{3+}$ in spinels but larger than that of sextet 1 , which is typical for tetrahedrally coordinated $\mathrm{Fe}^{3+}$. This indicates that the canted spins are mainly located in the $B$ sites.

At low temperatures the recoilless fractions for iron ions in the $A$ and $B$ sites are essentially equal, ${ }^{46}$ and therefore the area of the different components can give information about the cationic distribution. The ratio between $A$ (sextet 1) and $B$ (sextet 2 and sextet 3 ) sites $(\alpha)$ is remarkably similar for all the samples, indicating similar cationic distributions in the three samples. The $\alpha$ values are lower than those of a previous Mössbauer study of $\mathrm{CoFe}_{2} \mathrm{O}_{4}$ nanoparticles, and 
TABLE IV. Effective magnetic field $\left(B_{\text {eff }}\right)$, isomer shift $(\delta)$, quadrupole shift $(\varepsilon)$, ratio between the $A$ and $B$ components $(\alpha)$, relative area of the lines 2 and 5 for each component $\left(A_{2.5}\right.$ tot $)$ (the area of the lines 2 and 5 is normalized by the total area of the spectrum), canting angle $(\langle\theta\rangle)$ and cationic distribution. Uncertainties are given in parentheses as errors on the last digit.

\begin{tabular}{|c|c|c|c|c|c|c|c|c|}
\hline Sample & $\begin{array}{c}\text { Spectral } \\
\text { Component }\end{array}$ & $B_{\text {eff }}(\mathrm{T})$ & $\begin{array}{c}\delta \\
(\mathrm{mm} / \mathrm{s})\end{array}$ & $\begin{array}{c}\varepsilon \\
(\mathrm{mm} / \mathrm{s})\end{array}$ & $\begin{array}{c}\text { Area } \\
\text { ratio } \\
(\alpha=A / B)\end{array}$ & $\begin{array}{l}A_{2.5} \text { tot } \\
(\%)\end{array}$ & $\begin{array}{c}\langle\theta\rangle \\
(\operatorname{deg})\end{array}$ & $\begin{array}{c}\text { Cationic } \\
\text { distribution }\end{array}$ \\
\hline \multirow[t]{3}{*}{ N15 } & $\begin{array}{c}\text { Sextet } 1 \\
\text { (tetragonal- } A \text { site) }\end{array}$ & $55.8(2)$ & $0.38(2)$ & 0 & $0.35(3)$ & $15(1)$ & $38(1)$ & $\left(\mathrm{Co}_{0.48} \mathrm{Fe}_{0.52}\right)\left[\mathrm{Co}_{0.52} \mathrm{Fe}_{1.48}\right] \mathrm{O}_{4}$ \\
\hline & $\begin{array}{c}\text { Sextet } 2 \\
\text { (octahedral- } B \text { site) }\end{array}$ & $46.9(2)$ & $0.47(2)$ & 0 & & & & \\
\hline & $\begin{array}{c}\text { Sextet } 3 \\
\text { (canted spin) }\end{array}$ & $48.6(2)$ & $0.50(3)$ & 0.02 & & & & \\
\hline \multirow[t]{3}{*}{ N30 } & $\begin{array}{c}\text { Sextet } 1 \\
\text { (tetragonal- } A \text { site) }\end{array}$ & $55.8(2)$ & $0.38(3)$ & 0 & $0.39(3)$ & $15(1)$ & $37(1)$ & $\left(\mathrm{Co}_{0.44} \mathrm{Fe}_{0.56}\right)\left[\mathrm{Co}_{0.56} \mathrm{Fe}_{1.44}\right] \mathrm{O}_{4}$ \\
\hline & $\begin{array}{c}\text { Sextet } 2 \\
\text { (octahedral- } B \text { site) }\end{array}$ & $47.3(2)$ & $0.48(2)$ & 0 & & & & \\
\hline & $\begin{array}{c}\text { Sextet } 3 \\
\text { (canted spin) }\end{array}$ & $49.2(4)$ & $0.50(5)$ & 0.025 & & & & \\
\hline \multirow[t]{3}{*}{ N50 } & $\begin{array}{c}\text { Sextet } 1 \\
\text { (tetragonal- } A \text { site) }\end{array}$ & $55.2(2)$ & $0.38(3)$ & 0 & $0.34(3)$ & $22(1)$ & $46(1)$ & $\left(\mathrm{Co}_{0.49} \mathrm{Fe}_{0.51}\right)\left[\mathrm{Co}_{0.51} \mathrm{Fe}_{1.49}\right] \mathrm{O}_{4}$ \\
\hline & $\begin{array}{c}\text { Sextet } 2 \\
\text { (octahedral- } B \text { site) }\end{array}$ & $47.2(2)$ & $0.48(3)$ & 0 & & & & \\
\hline & $\begin{array}{c}\text { Sextet } 3 \\
\text { (canted spin) }\end{array}$ & $49.6(3)$ & $0.49(3)$ & 0.02 & & & & \\
\hline
\end{tabular}

this difference can be due to the preparation method of the material $^{46}$ and in particular, to the thermal treatment at high temperature. From these ratios, utilizing the formula $\left(\mathrm{Co}_{x} \mathrm{Fe}_{1-x}\right)\left[\mathrm{Co}_{1-x} \mathrm{Fe}_{1+x}\right],{ }^{47}$ where the round and the square brackets indicate $A$ and $B$ sites, respectively, we can obtain the cationic distributions that are reported in Table IV. It is quite clear that, within the experimental error, all the samples have the same cationic distribution.

The relative areas of lines 2 and 5 are quite similar for samples N15 and N30 but clearly larger for sample N50. Utilizing Eq. (6) it is possible to calculate the average value of the canting angles $(\langle\theta\rangle)$, reported in Table IV, that indicates a high degree of canting for all the samples, but it is most prominent in sample N50.

We have also measured a spectrum of sample N50 in a magnetic field of $6 \mathrm{~T}$ at $200 \mathrm{~K}$ in order to investigate the effect of temperature on the magnetic structure of the nanoparticles. Due to symmetry, a canted state with canting angle $\theta_{c}$ is commonly accompanied by another canted state with canting angle $-\theta_{c}{ }^{48}$ At finite temperatures, the thermal energy may be sufficient to overcome the energy barrier separating these two canted states, and the ions may then perform relaxation between the two states ${ }^{44,45,49}$ (transverse relaxation). In sample N50 the area of lines 2 and 5 in sextet 3 decreases from $\sim 22 \%$ to $\sim 17 \%$, while the widths of the lines increase by about $50 \%$ when the temperature is raised to $200 \mathrm{~K}$. The decrease of $A_{2,5}$ indicates transverse relaxation with a relaxation time comparable to or shorter than the time scale of Mössbauer spectroscopy. In fact, under these conditions, the effective magnetic field at the nucleus will be given by $B_{\text {eff }} \approx B_{\mathrm{hf}}^{0}\left\langle\cos \theta_{c}\right\rangle,{ }^{44,45}$ where $B_{\mathrm{hf}}^{0}$ is the hyperfine field if the canting is static. A further confirmation that transverse relaxation mainly affects the canted spins of the iron atoms located in the $B$ site is revealed from a reduction of $B_{\text {eff }}$ by $\sim 4 \mathrm{~T}$ at $200 \mathrm{~K}$ for sextet 3 and only $\sim 1 \mathrm{~T}$ for sextet 1 . In addition, the broadening of lines 2 and 5 at $200 \mathrm{~K}$ can (at least partly) be attributed to transverse relaxation with relaxation times of the same order of magnitude as the time scale of Mössbauer spectroscopy. $44,45,48$

\section{DISCUSSION}

Mössbauer spectroscopy and magnetization measurement have significantly different time scales, and for this reason the blocking temperatures estimated from the two techniques differ considerably. Inserting the time scales of magnetization measurement $\left(\tau_{m} \approx 100 \mathrm{~s}\right)$ and Mössbauer spectroscopy $\left(\tau_{M} \approx 5 \times 10^{-9} \mathrm{~s}\right)$ in Eq. (3) and values of $\tau_{0}$ $\approx 10^{-10}-10^{-12} \mathrm{~s}$ typical for ferrimagnetic materials in Eq. (3), one finds that the ratio $T_{B}^{M} / T_{B}^{m}$ should be in the range of $3-7 .{ }^{34}$ Considering that the value of $T_{\max }$ in ZFC magnetization measurements may be larger than $T_{B}^{m}$ by a factor $\beta$ $=1-2$, the ratio $T_{B}^{M} / T_{B}^{m}$ would be in the range of $2-7 .{ }^{34} \mathrm{In}$ Table III reported are the ratios $T_{B}^{M} / T_{B}^{m}$ and $T_{B}^{M} / T_{\max }$ for all the samples. Considering the experimental errors, N15 and N30 show values that are in quite good agreement with the theoretical calculations, while for sample N50 a lower value was obtained. This behavior of the more concentrated sample can be due to some interparticle interactions (a lower measuring time dependence of the blocking temperature is expected in this case), but an underestimate of $T_{B}^{m}$ may also play a role, since TRM measurement shows that there are still particles in the blocked state at $325 \mathrm{~K}$ and the value of the blocking temperature obtained from the anisotropy energy barrier distribution does not take these particles into 
account. Anyway, both the trend of the FC curve and the Mössbauer data suggest that the interparticle interactions are weak in this sample.

The magnetic properties of $\mathrm{CoFe}_{2} \mathrm{O}_{4}$ are strongly dependent on the distribution of the iron and cobalt ions in the $A$ and $B$ sites. As a rule, even small changes in the cationic distribution can result in substantial changes of magnetic moments and of the magnetic anisotropy. ${ }^{50}$ Usually, bulk cobalt ferrite has a partially inverse structure where the ratio $\alpha$ has been found to vary from 0.6 to 0.87 , depending on the thermal history of the sample. ${ }^{46}$ In nanoscaled particles the ratio between iron atoms located in $A$ sites and $B$ sites has been found lower, in the range from 0.67 (Refs. 36 and 51) and 0.5 (Ref. 47) for different synthesis methods. All the samples investigated in this paper show $\alpha$ values around 0.36 . The nearly constant value of $\alpha$ for all the samples is a very important result, because usually a reduction of the dimension leads to modification of the inversion degree and consequently to a variation of the magnetic properties. Instead the sol-gel autocombustion synthesis allows obtaining $\mathrm{CoFe}_{2} \mathrm{O}_{4}$ nanoparticles with cationic distribution independent of the particle size in a wide range of dimension $(7-28 \mathrm{~nm})$. This behavior is probably an intrinsic feature of the synthesis procedure.

To confirm the values of the anisotropy constants obtained from the temperature dependence of $\left\langle B_{\text {obs }}\right\rangle$, we determined the $K$ values combining TRM magnetometry and Mössbauer spectroscopy. Specifically, we inserted the blocking temperatures and the relaxation times corresponding to the time scales of the two techniques in Eq. (3) and calculated values of $K .^{33}$ For samples N15 and N30 the $K$ values obtained from the two methods (Table III) are in reasonable agreement, considering the possible effect of the interactions. A larger discrepancy is observed in sample N50 and this behavior may be due to an underestimate of $T_{B}^{m}$.

It should be remarked that the $K$ values are considerably smaller than the bulk value for $\mathrm{CoFe}_{2} \mathrm{O}_{4}$ [1.8-3.0 $\left.\times 10^{5} \mathrm{~J} \mathrm{~m}^{-3}\right]{ }^{50}$ This is surprising, because the magnetic anisotropy is usually larger in nanoscaled particles. ${ }^{41-43,52}$ The lower anisotropy in our samples can be explained by the lower value of $\alpha$ in the nanoparticles. A reduction of magnetic anisotropy due to a high percentage of $\mathrm{Co}^{2+}$ in tetrahedral sites has been observed earlier. ${ }^{53}$ This can be explained by the smaller single ion anisotropy for $\mathrm{Co}^{2+}$ located in tetrahedral sites $\left({ }^{4} A_{2}\right.$ crystal field ground energy term) $\left(-79 \times 10^{-24} \mathrm{~J} /\right.$ ion $)$ compared to $\mathrm{Co}^{2+}$ in octahedral sites $\left(+850 \times 10^{-24} \mathrm{~J} /\right.$ ion) (the larger magnetocrystalline anisotropy is related to the orbital contribution in the ${ }^{4} T_{1}$ ground energy term). ${ }^{54,55}$

A change in the cationic distribution implies a variation in the saturation magnetization, and for a correct evaluation of magnetic properties in our samples it is necessary to recalculate a new reference value of $M_{s}$. Assuming that the $\mathrm{Fe}^{3+}$ and $\mathrm{Co}^{2+}$ ions have a moment of $5 \mu_{B}$ and $3 \mu_{B}$, respectively, and neglecting the spin canting, our samples have a magnetic moment per unit chemical formula of about $4.9 \mu_{B}$ that corresponds to a saturation magnetization of $116 \mathrm{~A} \mathrm{~m}^{2} \mathrm{~kg}^{-1}$. All the samples show a significant reduction of $M_{s}$ with respect to this theoretical value. Sample N15 shows a larger reduction, probably due to the presence of particles still in the superparamagnetic state at low temperature. The reduction of $M_{s}$ can be explained by to the presence of a noncollinear spin structure, as shown by the high magnetic field Mössbauer spectra.

Samples N30 and N15 show remarkably similar values of $A_{2,5}$, within the experimental error, while sample N50 presents a slightly larger canting. This result is quite interesting in the general discussion about the noncollinear structure in the magnetic nanoparticles. In fact, the presence of similar canting in the three samples with the largest degree of canting in the largest particles indicates that the spin canting is not a surface phenomenon but that it is an effect that is more or less uniform throughout the volume of the particles.

\section{CONCLUSIONS}

The dispersion of cobalt ferrite nanoparticles in a silica matrix through sol-gel autocombustion method allows to obtain assemblies of weakly interacting particles. The sol-gel autocombustion synthesis results in nanoparticles with a cationic distribution that is independent of the particle size $(7-28 \mathrm{~nm})$ and with a very low inversion degree that leads to important modifications of the magnetic properties of the material. We have determined the magnetic anisotropy constants of cobalt ferrite nanoparticles from the temperature dependence of the magnetic hyperfine splitting in Mössbauer spectra at low temperatures and from the blocking temperatures estimated from Mössbauer spectroscopy and magnetization measurements. The values estimated by the two methods are in good agreement, and it is found that the anisotropy constant increases with decreasing particle size. However, surprisingly, it is found that the anisotropy constants are smaller than the bulk value. We show that this can be explained by a cationic distribution, which differs considerably from that usually found in bulk cobalt ferrite.

Finally, the samples N15 and N30 show large but similar fractions of canted spins, indicating that the fraction of canted spins is only weakly dependent on the particle size in the range of $6-17 \mathrm{~nm}$. This result indicates that the spin canting is not simply a surface phenomenon but also occurs in the interior of the particles.

${ }^{1}$ I. Matsui, J. Chem. Eng. Jpn. 38, 535 (2005).

${ }^{2}$ R. E. Rosensweig, Chem. Eng. Prog. 85, 53 (1989).

${ }^{3}$ A. S. Edelstein and R. C. Cammarata, Nanomaterials: Synthesis, Properties and Applications (Institute of Physics, Bristol, 1996).

${ }^{4}$ P. Tartaj, M. P. Morales, S. Veintemillas-Verdaguer, T. Gonzales Cárreño, and C. J. Serna, J. Phys. D 36, R182 (2003).

${ }^{5}$ J. L. Dormann, D. Fiorani, and E. Tronc, Advances in Chemical Physics (Wiley, New York, 1997), Vol. XCVIII, p. 283.

${ }^{6}$ J. M. D. Coey, Phys. Rev. Lett. 27, 1140 (1971).

${ }^{7}$ A. H. Morrish and K. Haneda, J. Magn. Magn. Mater. 35, 105 (1983).

${ }^{8}$ E. Tronc, A. Ezzir, R. Cherkaoui, C. Chanéc, M. Noguès, H. Kachkachi, D. Fiorani, A. M. Testa, J. M. Grenèche, and J. P. Jolivet, J. Magn. Magn. Mater. 221, 63 (2000).

${ }^{9}$ A. H. Morrish, K. Haneda, and P. J. Schurer, J. Phys. C 37, 6 (1976).

${ }^{10}$ T. Okada, H. Sekizawa, F. Ambe, and T. Yamada, J. Magn. Magn. Mater. 105, 31 (1983).

${ }^{11}$ F. T. Parker, M. W. Foster, D. T. Margulies, and A. E. Berkowitz, Phys. Rev. B 47, 7885 (1993).

${ }^{12}$ C. Liu, B. Zou, A. J. Rondinone, and Z. J. Zhang, J. Am. Chem. Soc. 122, 6263 (2000).

${ }^{13}$ C. Liu, A. J. Rondinone, and Z. J. Zhang, Pure Appl. Chem. 72, 37 
(2000).

${ }^{14}$ A. R. West, Solid State Chemistry (Wiley, New York, 1984).

${ }^{15}$ J. P. Chen, K. J. Klabunde, G. C. Hadjipanayis, E. Devlin, and A. Kostikas, Phys. Rev. B 54, 9288 (1996).

${ }^{16}$ C. R. Vestal and Z. J. Zhang, Chem. Mater. 14, 3817 (2002).

${ }^{17}$ S. Komarneni, J. Mater. Chem. 2, 1219 (1992).

${ }^{18}$ M. Wu, Y. Xiong, Z. Peng, N. Jang, H. Qi, and Q. Chen, Mater. Res. Bull. 39, 1875 (2004).

${ }^{19}$ H. Guerrero, G. Rosa, M. P. Morales, F. del Monte, E. M. Moreno, D. Levy, R. Pèrez del Real, T. Belenguer, and C. J. Serna, Appl. Phys. Lett. 71, 2968 (1998).

${ }^{20}$ D. Chakraborty, Bull. Mater. Sci. 15, 411 (1992).

${ }^{21}$ B. L. Yang, F. Hong, and H. H. Kung, J. Phys. Chem. 88, 2351 (1984).

${ }^{22}$ C. Suryanarayana, Bull. Mater. Sci. 17, 307 (1994).

${ }^{23}$ C. Cannas, A. Musinu, D. Peddis, and G. Piccaluga, Chem. Mater. 18, 3835 (2006).

${ }^{24}$ C. Cannas, A. Musinu, D. Peddis, and G. Piccaluga, J. Nanopart. Res. 6, 223 (2004).

${ }^{25}$ A. H. Morrish, The Physical Principles of Magnetism (Wiley, New York, 1965), p. 394.

${ }^{26}$ C. Cannas, D. Gatteschi, A. Musinu, G. Piccaluga, and C. Sangregorio, J. Phys. Chem. B 102, 7721 (1998).

${ }^{27}$ M. F. Hansen and S. Mørup, J. Magn. Magn. Mater. 203, 214 (1999).

${ }^{28}$ J. L. Gittleman, B. Abels, and S. Rozowski, Phys. Rev. A 9, 3891 (1974).

${ }^{29}$ R. D. Zysler, D. Fiorani, and A. M. Testa, J. Magn. Magn. Mater. 224, 5 (2001).

${ }^{30}$ R. W. Chantrell, M. El-Hilo, and K. O'Grady, IEEE Trans. Magn. 27, 3570 (1991).

${ }^{31}$ A. J. Rondinone, A. C. S. Samia, and Z. J. Zhang, J. Phys. Chem. B 103, 6876 (1999).

${ }^{32}$ L. Del Bianco, D. Fiorani, A. M. Testa, E. Sonetti, L. Savini, and S Signorotti, Phys. Rev. B 66, 174418 (2002).

${ }^{33}$ D. P. E. Dickson, N. M. K. Reid, C. Hunt, H. D. Williams, M. El-Hilo, and K. O'Grady, J. Magn. Magn. Mater. 125, 345 (1993).

${ }^{34}$ S. Mørup, F. Bødker, P. V. Hendriksen, and S. Linderoth, Phys. Rev. B 52, 287 (1995).
${ }^{35}$ C. P. Bean and J. D. Livingston, J. Appl. Phys. 30, 1205 (1959).

${ }^{36}$ N. Moumen, P. Bonville, and M. P. Pileni, J. Phys. Chem. 100, 14410 (1996).

${ }^{37}$ M. F. Hansen, C. B. Koch, and S. Mørup, Phys. Rev. B 62, 1124 (2000).

${ }^{38}$ S. Mørup, C. Frandsen, F. Bødker, S. N. Klausen, K. Lefmann, P. A. Lindgard, and M. F. Hansen, Hyperfine Interact. 144/145, 347 (2002).

${ }^{39}$ S. Mørup and H. Topsøe, Appl. Phys. 11, 63 (1976).

${ }^{40}$ S. Mørup, J. Magn. Magn. Mater. 37, 39 (1983).

${ }^{41}$ F. Bødker, S. Mørup, and S. Linderoth, Phys. Rev. Lett. 72, 282 (1994).

${ }^{42}$ F. Bødker and S. Mørup, Europhys. Lett. 52, 217 (2000).

${ }^{43}$ E. Tronc, Nuovo Cimento D 18, 163 (1996).

${ }^{44}$ Ö. Helgason, H. K. Rasmussen, and S. Mørup, J. Magn. Magn. Mater. 302, 413 (2006).

${ }^{45}$ T. A. Anhøj, B. Bilenberg, B. Thomsen, C. D. Damsgaard, H. K. Rasmussen, C. S. Jacobsen, J. Mygind, and S. Mørup, J. Magn. Magn. Mater. 260, 115 (2003).

${ }^{46}$ G. A. Sawatzky, F. Van der Woude, and A. H. Morrish, Phys. Rev. 187, 747 (1969).

${ }^{47}$ K. Haneda and A. H. Morrish, J. Appl. Phys. 8, 4258 (1988).

${ }^{48}$ S. Mørup, J. Magn. Magn. Mater. 266, 110 (2003).

${ }^{49}$ J. L. Dormann, M. El Harfaoui, M. Noguès, and K. Jove, J. Phys. C 20, L161 (1987).

${ }^{50}$ V. Blaskov, V. Pektov, V. Rusanov, M. Ll. Martinez, B. Martinez, J. S. Muñoz, and M. Mikhov, J. Magn. Magn. Mater. 162, 331 (1996).

${ }^{51}$ C. N. Chinnasamy, B. Jeyadevan, K. Shinoda, K. Tohji, D. J. Djayaprawira, M. Takahashi, R. Justin Joseyphus, and A. Narayanasamy, Appl. Phys. Lett. 83, 2862 (2003).

${ }^{52}$ L. D. Tung, V. Kolesnichenko, D. Caruntu, N. H. Chou, C. J. O’Connor, and L. Spinu, J. Appl. Phys. 93, 7486 (2003).

${ }^{53}$ G. Hu, J. H. Choi, C. B. Eom, V. G. Harris, and Y. Suzuki, Phys. Rev. B 62, 779 (2000).

${ }^{54}$ H. Y. Zhang, B. X. Gu, H. R. Zhai, Y. Z. Miao, S. Y. Zhang, and H. B. Huang, J. Appl. Phys. 75, 7099 (1994).

${ }^{55}$ M. D. Sturge, E. M. Gyorgy, R. C. LeCraw, and J. P. Remeika, Phys. Rev. 180, 413 (1969) 